\title{
¿Ficción o realidad? El valor sociológico de Relato de un náufrago de Gabriel García Márquez
}

\author{
Fiction or reality? Gabriel García Márquez's \\ Relato de un náufrago sociological value
}

\section{Ascensión Rivas HeRnándeZ}

Universidad de Salamanca. Salamanca, España.

sisina@usal.es

\section{RESUMEN}

Hay obras que no nacen con vocación literaria, pero al final acaban convertidas en literatura. Es lo que sucede con Relato de un náufrago, novela corta de Gabriel García Márquez, desde que apareció con ese título en el año 1970. Antes lo había hecho en forma de reportaje periodístico, en catorce entregas, en el diario El Espectador de Bogotá. Entre ambos textos no hay diferencias de contenido, pero el "Prólogo" que antecede a la edición del 70 es muy significativo: aporta datos sobre el protagonista que desdicen la imagen que se daba de él en 1955; cuenta los motivos del naufragio, que salpicaron y acabaron con la dictadura de Rojas Pinilla; dice qué fue del héroe pasados los años, e insinúa los motivos de la publicación de aquel reportaje en forma de libro quince años después. La interpretación de la obra es diferente según se lea o no este "Prólogo". Todo ello revela el papel sociológico de la literatura: un acontecimiento histórico que se convierte en ficcional, y que, desde su posición como objeto literario, influye después en la realidad. En el artículo se analizarán todos estos aspectos, así como los elementos literarios del relato y aquellos otros que lo vinculan con la realidad.

Palabras claves: Historia, literatura, realidad, periodismo, sociología. 


\section{ABSTRACT}

There are works that are not born with literary vocation, but they eventually end up in literature. This is what happens in Relato de un náufrago, a short novel by Gabriel García Márquez since its appearance with that title in 1970. Beforehand, the text had appeared in the form of newspaper reporting in fourteen deliveries in the Bogotá newspaper El Espectador. There is no difference in content between both texts, but the "Prologue" that precedes the edition of 70 is very significant: it provides data on the character that belies the image that it was in 1955; enumerates the reasons for the sinking, which splashed and overthrew the dictator Rojas Pinilla; says what happened with the hero, and suggests the reasons why that text was published as a book fifteen years later. The reading of the work is different as read or not this "Prologue". This paper reveals the sociological literature value: a historical event that becomes fictional, and that from his position as a literary object, influences then in reality. The paper will analyze all these aspects and literary elements of narrative and those that link it to the reality.

Keywords: History, literature, reality, journalism, sociology.

Recibido: 28/12/2010. Aceptado: 22/03/2011.

\section{EL "PRÓLOGO" DE 1970 O "LA HISTORIA DE ESTA HISTORIA"}

abriel García Márquez escribió Relato de un náufrago en 1955 para ser T publicado de forma seriada en el diario El Espectador de Bogotá. El texto, que entonces se tituló "La verdad sobre mi aventura" de una historia realmente acontecida. El 28 de febrero de ese año habían desaparecido ocho marineros del destructor Caldas después de haber caído al agua durante una tormenta en el Caribe. El buque alcanzó tierra en Cartagena y al poco tiempo se suspendió la búsqueda de los infortunados, a los que se dio por muertos. Pero diez días más tarde, cuando nadie lo esperaba, apareció uno de los náufragos en una playa colombiana. El Relato es el resultado de lo que el superviviente, Luis Alejandro Velasco, le contó al reportero

${ }^{1}$ Se publicó en abril de 1955, en catorce entregas, pero ya antes García Márquez había escrito otros artículos sobre el suceso: "El náufrago sobreviviente pasó los once días en una frágil balsa", "Oficina de información exclusiva para el náufrago crea la Marina” y "La explicación de una odisea en el mar", publicados en El Espectador en marzo de 1955. 
García Márquez sobre su aventura en el mar.

El texto cuenta con dos versiones. La primera es la de 1955, y reproduce el reportaje periodístico elaborado por García Márquez tras escuchar al superviviente; la segunda, que data de febrero de 1970, incorpora un Prólogo en el que el creador colombiano aclara algunas circunstancias sobre el texto principal. Está escrito por un narrador homodiegético y firmado con las iniciales G. G. M., que corresponden al nombre del autor. Se trata de una explicación sobre la naturaleza del relato del náufrago, aunque también se habla allí de la génesis del texto y se ofrece un nuevo punto de vista sobre el personaje y sobre la historia que amplía la visión de ambos y pone de relieve el carácter literario o ficcional de la obra. De hecho, la interpretación es diferente según el lector se haga o no eco del Prólogo. En ello reside su valor y su interés. En relación con el origen del relato, García Márquez señala lo siguiente:

Mi primera sorpresa fue que aquel muchacho de veinte años, macizo, con más cara de trompetista que de héroe de la patria, tenía un instinto excepcional del arte de narrar, una capacidad de síntesis y una memoria asombrosas, y bastante dignidad silvestre como para sonreírse de su propio heroísmo. En veinte sesiones de seis horas diarias, durante las cuales yo tomaba notas y soltaba preguntas tramposas para detectar sus contradicciones, logramos reconstruir el relato completo y verídico de sus diez días en el mar. Era tan minucioso y apasionante, que mi único problema literario sería conseguir que el lector lo creyera. No fue sólo por eso, sino también porque nos pareció justo, que acordamos escribirlo en primera persona y firmado por él. Esta es, en realidad, la primera vez que mi nombre aparece vinculado a este texto (García Márquez, 1984 [1970: 11)².

El interés de este texto es múltiple. En primer lugar, reproduce una breve descripción física del protagonista, que no aparece en el relato del náufrago en primera persona porque iría contra la verosimilitud; además, se valora extraordinariamente el instinto narrativo de Velasco, su capacidad de síntesis y su excepcional memoria, todo lo cual redunda, de nuevo, en la verosimilitud; también se destaca su sentido irónico de los hechos, que le permite reírse de su propio heroísmo. Pero no se alude, sin embargo, a un rasgo que caracteriza al personaje tal como se le representa en el interior de la obra, es decir, a su bondad natural. Contrariamente, y esto es lo significativo por

\footnotetext{
${ }^{2}$ En adelante cito por la misma edición.
} 
oposición, se destaca su capacidad para hacer dinero con el suceso. Para terminar, se cuenta el origen del texto y, lo más relevante, García Márquez proclama su autoría. La intención del colombiano es "reconstruir el relato compacto y verídico de sus diez días en el mar", es decir, quiere reproducir los hechos con veracidad, como le interesa al periodismo. Pero lo más destacable, al ver lo minuciosa y apasionante que era la narración de Luis Alejandro Velasco, es que el problema del autor era "conseguir que el lector lo creyera”. Desde el principio, pues, y dada la naturaleza del relato, surgen dudas sobre la credibilidad. Sin embargo, lo cierto es que la obra resulta perfectamente verosímil, y que el lector no sólo se la cree, sino que, además, se figura al náufrago escribiéndola. Esto se logra con un estilo aparentemente sencillo que se ajusta a la personalidad y a la formación de un marino de veinte años, y al uso de la homodiégesis.

En el Prólogo de 1970 Gabriel García Márquez afirma que la novela apareció narrada en primera persona y firmada por el protagonista por dos razones fundamentales: para contribuir a su credibilidad -extremo que, en efecto, se corrobora- y porque a los que intervinieron en su organización y redacción -periodista y protagonista de los hechos- les pareció justo. Sin embargo, hay una tercera razón que no se expresa pero que se evidencia después de que el tiempo ha situado a cada uno en el lugar que le corresponde. En 1955 Gabriel García Márquez no era el autor de culto que llegó a ser después, sino un reportero que escribía para un periódico. Lo verdaderamente revelador es el hecho de que en aquel momento García Márquez no era un hombre prestigioso y sí lo era el náufrago protagonista. Un relato así presentado sólo es posible cuando el autor real es un desconocido para el público, porque si no lo fuera, nadie tendría interés en que permaneciera en el anonimato, y menos aún la editorial. En su primera edición como texto para el periódico valía más la obra firmada por su protagonista, pero ya en 1970 era más apreciada con la firma de G. G. M., lo que pone de relieve ese valor sociológico de la literatura que depende de las circunstancias y del tiempo en que aparece. Así lo corrobora el escritor colombiano al final del Prólogo cuando afirma lo siguiente:

Yo no había vuelto a leer este relato desde hace quince años. Me parece bastante digno para ser publicado, pero no acabo de comprender la utilidad de su publicación. Si ahora se imprime en forma de libro es porque dije sí sin pensarlo muy bien, y no soy hombre con dos palabras. Me deprime la idea de que a los editores no les interese tanto el mérito del texto como el nombre con que está firmado, que muy a mi pesar es el mismo de un 
escritor de moda. Por fortuna, hay libros que no son de quien los escribe sino de quien los sufre, y éste es uno de ellos (13).

Como señala García Márquez, pues, si el relato sale a la luz en 1970 en forma de libro, es por puro interés editorial, debido al Boom de la literatura hispanoamericana y, sobre todo, al éxito alcanzado por la publicación de Cien años de soledad en 1967. Al final, no obstante, se proclama autor del libro, pero declara, así mismo, que éste no es suyo sino de quien lo sufrió. El problema que se plantea entonces es el de repartir los méritos con justicia, pero esto resulta imposible.

Inicialmente el texto se publicó de forma consecutiva a lo largo de catorce días, y su éxito fue absoluto. El lector del periódico, como sucediera en la época de los folletines ${ }^{3}$, se sintió fascinado desde el principio por la narración del náufrago:

[...] la circulación del periódico estaba casi doblada, y había frente al edificio como una rebatiña de lectores que compraban los números atrasados para conservar la colección completa (12).

Desde el origen mismo, pues, el relato cumplió las expectativas de su autor. Los problemas llegaron después cuando, por casualidad, el reportero descubre que tras la ingenua narración del marinero Velasco se esconde un caso de corrupción que salpica la dictadura militar del general Gustavo Rojas Pinilla. Y éste es otro de los grandes méritos del relato, vinculado, una vez más, al valor sociológico de la literatura.

La censura estaba instalada en la prensa y los reporteros tenían que lidiar a diario con las imposiciones del régimen, peleando por escamotear a sus lectores noticias de carácter político que hicieran recelar sobre la dictadura ${ }^{4}$. De hecho, Luis Alejandro Velasco había sido retenido en un hospital hasta su recuperación tras el naufragio, y ningún reportero independiente había podido hablar con él, temeroso el régimen de que contase lo que no se podía saber sobre la verdad de los hechos. Pero con el paso del tiempo, el náufrago mudó a un segundo plano social, y la versión oficial de la historia parecía no

${ }^{3}$ Así lo cuenta Pérez Galdós en El crimen de la calle de Fuencarral (2002: 25 y 41), y lo mismo sucede con la publicación seriada de A sangre fría de Truman Capote (Clarke: 1993: 374-376). "La verdad sobre mi aventura” tuvo tanto éxito que se reeditó en un suplemento especial el 28 abril, ilustrado con las fotografías de los marineros y precedido dos días antes por una nota anónima en primera plana en la que se decía con orgullo: "El Espectador imprimirá [...] la edición más numerosa que periódico alguno haya publicado jamás en Colombia” (Gilard, 1982: 61).

${ }^{4}$ Sobre la censura política y la escritura de García Márquez, véase Méndez (1989: 8). 
dar más de sí. Esta pasaba por afirmar que el siniestro se había producido por causa de una tempestad, y no, como en realidad había sucedido, porque un golpe de viento había desplazado la carga que, de forma fraudulenta, se transportaba en el barco. Ahí es donde García Márquez consigue su triunfo, ya que al preguntar directamente por la tormenta, el náufrago le responde que la caída de los marineros al mar fue debida, en realidad, a que los electrodomésticos que estaban sobre la cubierta se desplazaron y esto hizo zozobrar el barco. Como señala Díez Huélamo (1986: 18) a este respecto, "[E] sta declaración era explosiva, porque un destructor de la Armada no podía transportar carga comercial alguna y, mucho menos, de contrabando, como era el caso". Desde el aparato del poder se negó tajantemente la nueva versión que se iba publicando en El Espectador, pero con la ayuda de los marineros, los reporteros consiguieron las fotografías del viaje, que evidenciaban la verdad de lo sucedido. Este es el motivo de que el relato que el reportero García Márquez fue dando a la luz en el diario de Bogotá hiciera tambalear el régimen dictatorial. Pero además, y a consecuencia de ello, el periódico fue clausurado, el héroe fue devuelto al anonimato y el periodista autor del texto, Gabriel García Márquez, fue enviado a Europa como corresponsal durante un año ${ }^{5}$, según señala en el Prólogo:

Lo que no sabíamos ni el náufrago ni yo cuando tratábamos de reconstruir minuto a minuto su aventura, era que aquel rastreo agotador habría de conducirnos a una nueva aventura que causó un cierto revuelo en el país, que a él le costó su gloria y su carrera y que a mí pudo costarme el pellejo (9).

La estimación de la literatura es aquí extraordinaria, y a la luz de lo que sucedió después no resulta baladí plantear el problema de las relaciones entre realidad y ficción, porque se trató de un hecho real que, contado de forma literaria, tuvo consecuencias reales para todos los protagonistas.

En este sentido, además, el Prólogo es interesante porque da noticia de lo que fue del personaje pasados los años. En el momento de la escritura, el entonces náufrago y héroe es un hombre anónimo, olvidado por todos

${ }^{5}$ En julio de 1955 fue enviado a Ginebra a cubrir la Conferencia de los Cuatro Grandes, pero una semana después se traslada a Roma donde sigue la enfermedad de Pío XII y donde permanece hasta finales de ese año. Desde allí se traslada a París, y a los pocos días de llegar se entera de que la dictadura ha clausurado El Espectador, lo que le deja sin trabajo y sin fuente de financiación. En París se dedica de lleno a la literatura mientras sufre una situación económica de precariedad (Méndez, 1989: 11). 
tras el silencio al que lo arrojó la dictadura, como dice el autor al final de la introducción:

Nadie volvió a saber nada del náufrago solitario, hasta hace unos pocos meses en que un periodista extraviado lo encontró detrás de un escritorio en una empresa de autobuses. He visto esa foto: ha aumentado de peso y de edad, y se nota que la vida le ha pasado por dentro, pero le ha dejado el aura serena del héroe que tuvo el valor de dinamitar su propia estatua (13).

El cuerpo central de la obra está constituido por lo que ya se publicó en 1955 en catorce capítulos, pero el prólogo de 1970 introduce nuevas claves de lectura sobre la obra y, sobre todo, muestra los entresijos de la escritura del Relato.

Otro problema es el de determinar el carácter literario de la obra. En este sentido, Díez Huélamo (1986: 41-42) señala, a mi juicio equivocadamente, que ese componente no estaba en el texto inicial, y que éste se consigue quince años después debido a tres diferencias sustanciales. En primer lugar se refiere al prólogo, que sintetiza las "circunstancias históricas" del naufragio, refiere las causas de éste y los problemas de censura, y "pone de manifiesto la voluntad literaria del autor, que se hace responsable del escrito atribuido en 1955 al propio náufrago" (42). En mi opinión, sin embargo, el texto central tiene valor literario por sí mismo, y en este sentido esa "voluntad literaria del autor" ya estaba en el relato de 1955, como mostraré después. La autoatribución de responsabilidad por parte de García Márquez en el Prólogo de 1970 no deja de ser algo externo, desprovisto de contenido literario alguno ${ }^{6}$. Díez Huélamo continúa su argumentación señalando que la modificación del título también aporta contenido literario en un doble sentido: "por un lado [...] atribuye las notas de universalidad y acronía mediante el cambio de la primera persona ( $m i$ aventura) por la tercera (un náufrago)”. Además, continúa, "el valor característicamente periodístico resaltado en el título de 1955 (la verdad) se subordina a su valor literario, al adscribir el texto a un género (Relato) formulado convencionalmente en la tradición literaria" (42). Pero lo cierto es que cualquier obra con carácter literario puede estar encabezada por la fórmula que prefiera el autor, y que ello no es óbice para su literariedad, contenga aquélla los términos "relato" o "verdad". Y aunque

\footnotetext{
${ }^{6}$ Además, como señala Gilard (1982: 67), cuando se notificó que el reportaje se reeditaría completo en un suplemento especial, en la nota que acompañaba el anuncio ya se hablaba de García Márquez en relación con la autoría: "para asesorar al autor (Velasco), este diario asignó a uno de sus cronistas más experimentados y capaces, nuestro redactor Gabriel García Márquez”.
} 
es posible, quizá, que el título del reportaje ("La verdad sobre mi aventura”) convenga más a un texto periodístico que a uno meramente ficcional, también lo es que el título completo de la novela corta (Relato de un náufrago que estuvo diez dias a la deriva sin comer ni beber, que fue proclamado héroe de la patria, besado por las reinas de la belleza y hecho rico por la publicidad, $y$ luego aborrecido por el gobierno y olvidado para siempre) no encaja con una publicación de este género. Más bien al contrario, parece una ironía del autor, decidido a utilizar un epígrafe de dimensiones exageradas. En tercer lugar, continúa Díez Huélamo, hay que tener en cuenta el cambio de nombre de las catorce entregas, que en el Relato pasaron a denominarse capitulos, de modo que, "al hacer uso de un tan significativo concepto narrativo, el autor ahondaba en la literatización de su obra” (42). En este sentido, la denominación de capitulo a cada una de las catorce entregas que aparecieron en $E l$ Espectador de Bogotá es un hecho que se deriva sencillamente del nuevo exergo del texto, es decir, de su edición en formato de libro. La designación de capitulos, en realidad, y dejando al margen que este término suele aparecer en los libros, no es, en absoluto, un elemento literaturizador, sino una consecuencia natural del nuevo estatus del texto.

\section{EL REPORTAJE PERIODÍSTICO DE 1955 O VERDADERO RELATO DEL NÁUFRAGO}

Como ya he señalado, el reportaje periodístico que se publicó en catorce entregas en El Espectador de Bogotá tenía como título genérico "La verdad sobre mi aventura”, y constituye, tras su edición en forma de libro, el núcleo central de la publicación. Se trata de un texto elaborado por un reportero que cuenta como informador oral con el protagonista de los hechos, y que tiene dos características fundamentales entre las que oscila: la narración objetiva y realista de lo que pasó y el carácter literario que imprime el autor a la narración.

\subsection{OBJETIVIDAD Y REALISMO DEL RELATO}

El realismo y la objetividad son aspectos consustanciales al periodismo y, por lo tanto, fundamentales en un escrito que nace con voluntad informativa, para ser leído en un diario. Ambos aspectos se consiguen con el uso de distintos artificios, entre ellos el narrador homodiegético. De esta manera, el contenido es más verosímil, ya que, como el que cuenta la historia es el 
protagonista de los hechos, nadie mejor que él puede saber lo que pasó, cómo pasó o qué sintió el héroe, sobre todo en una historia que reconstruye un naufragio y en la que sólo hay un personaje ${ }^{7}$.

La narración, además, es muy sencilla, como corresponde por su formación y por su cultura a un marinero de veinte años. Independientemente de que el relato esté literaturizado -y en ocasiones muy literaturizado según mostraré después- el periodista hizo un trabajo importante en favor de la verosimilitud. En este sentido, además, en la obra se mantienen, a menudo, rasgos de esa exposición oral que está en su origen. Los "he dicho" que aparecen sobre todo al principio, son un indicio de la oralidad, y contribuyen a dotar a la narración de credibilidad y de realidad.

Como sucede en la mayor parte de los relatos en primera persona ${ }^{8}$, la narración tiene lugar una vez que han sucedido los acontecimientos. Esto significa que el narrador conoce todo lo pasado cuando inicia el acto de la escritura. En el caso del Relato, además, el hecho es más natural y verosímil, porque el náufrago sólo pudo contar la historia después de haber regresado a la civilización, es decir, una vez finalizada su aventura en el mar en solitario. A pesar de las abundantes anticipaciones y retrospecciones, que son un elemento de la literaturización, el autor implícito habitualmente privilegia la posición del personaje, de manera que obliga al lector a vivir la peripecia desde la perspectiva del náufrago. Esto se ve muy claro en el tratamiento general del tiempo. Al principio, el narrador introduce referencias muy precisas y continuadas con el fin de que el receptor comprenda el lento y subjetivo transcurrir de los minutos desde la perspectiva del protagonista (Molina Fernández, 2006: 76-82):

${ }^{7}$ García Márquez se ha referido al carácter periodístico de la obra y a lo que eso comporta: "[Relato de un náufrago] está más cerca de la crónica, porque es la transcripción organizada de una experiencia personal contada en primera persona por el único que la vivió. En realidad es una entrevista larga, minuciosa, completa, que hice a sabiendas de que no era para publicar en bruto sino para ser cocinada en otra olla: un reportaje. No tuve nada que forzar porque fue como pasearme por una pradera de flores con la posibilidad suprema de escoger las mejores. Y esto lo digo en homenaje a la inteligencia, el heroísmo y la integridad del protagonista que, con justicia, fue el náufrago más querido del país" (García Márquez, 2001).

Y se refiere también al modo de llevar a cabo la entrevista: "No usamos grabadoras porque las mejores de aquel tiempo eran tan grandes y pesadas como una máquina de coser, y el hilo metálico se embrollaba como cabellos de ángel. Aún hoy sabemos que son muy útiles para recordar, pero nunca hay que descuidar la cara del entrevistado, que puede dar mucho más que su voz, y a veces todo lo contrario. Tuve que tomar notas en un cuaderno de escuela, y eso me obligó a no perder ni una palabra ni un matiz de la entrevista, y a tratar de profundizar a cada paso" (Ibidem).

${ }^{8}$ En todos menos en el diario, y en este caso, además, considerada en su conjunto toda la narración, porque incluso si el autor se pone a escribir al final del día o de una secuencia temporal concluida, tiene un conocimiento global de lo vivido durante la misma. 
La última vez que Luis Rengifo me preguntó la hora, en el destructor, eran las once y media. Vi nuevamente la hora a las once y cincuenta, y todavía no había ocurrido la catástrofe. Cuando miré el reloj en la balsa, eran las doce en punto (35).

Al lado del relato en primera persona, del estilo sencillo, de la oralidad y de la verosimilitud, hay que situar el realismo, elemento, como los otros, buscado por el autor implícito en un texto originariamente periodístico. Al narrador le interesa contar la situación vivida por el náufrago con una intensidad parecida a la que sintió el personaje, es decir, le preocupa transmitir los acontecimientos del modo más fiel a como tuvieron lugar. De esta manera se cuenta, por ejemplo, la descripción de lo que siente Velasco cuando despluma la gaviota (63), o la pérdida de la balsa cuando un vendaval la vuelca tras siete días de naufragio en soledad:

Pocos minutos después de las doce de la noche una ola enorme -tan grande como la que barrió la cubierta del destructor- levantó la balsa como una cáscara de plátano, la enderezó primero hacia arriba, y en una fracción de segundo la hizo dar una vuelta de campana.

Me di cuenta de todo cuando estaba en el agua, nadando hacia arriba, como en la tarde del accidente. Nadé desesperadamente, salí a la superficie y me sentí morir de terror: no vi la balsa. Vi las enormes olas negras sobre mi cabeza y me acordé de Luis Rengifo, un hombre fuerte, un buen nadador bien alimentado que no pudo alcanzar la balsa a dos metros de distancia. Me había desorientado y estaba buscando la balsa por el lado contrario (78).

\subsection{CARÁCTER LITERARIO DEL RELATO}

Tal como se entendía a mediados del siglo XX, el reportaje era un género híbrido entre la literatura y el periodismo en el que los aspectos estéticos y ficcionales eran elementos tan indispensables como la objetividad, la verosimilitud y el realismo (Chillón, 1999: 185-195).

El carácter literario del Relato se aprecia en elementos tanto del estilo como de la narración, y por eso es frecuente un uso muy cuidado del lenguaje que revela la mano maestra del autor. Así se pone de manifiesto en el siguiente fragmento, donde dominan los paralelismos y la abundancia de adjetivos de color, conformando un estilo que recuerda más al de una novela que al de un simple reportaje periodístico: 
De pronto el cielo se puso rojo, y yo seguía escrutando el horizonte. Luego se puso color de violetas oscuras, y yo seguía mirando. A un lado de la balsa, como un diamante amarillo en el cielo color vino, fija y cuadrada, apareció la primera estrella. Fue como una señal. Inmediatamente después, la noche, apretada y densa, se derrumbó sobre el mar (39).

Pero además, en la narración también se perciben huellas de la literaturización del texto. No sólo es que aparezcan diálogos que han tenido que ser necesariamente recreados, sino que además hay una dosificación de la información, necesaria para que el relato resulte como quiere el autor implícito. Porque aunque el narrador aparentemente está contando los hechos de forma objetiva, en realidad los está seleccionando, y al hacerlo, está dando la información necesaria para producir el efecto que desea.

El carácter literario de la narración también se observa en los recursos utilizados para variar el curso lineal del tiempo. Las prolepsis y las analepsis se emplean para dotar al relato de variedad y amenidad. Este hecho es importante porque permite organizar el universo narrativo y dosificar la información, anticipando, si así le interesa al narrador, acontecimientos que en realidad sucedieron con posterioridad en el tiempo. Por este motivo, cuando se quiere crear suspense sobre lo que ocurrió después, o se desea introducir desasosiego y tensión, se utiliza la prolepsis, y se hace de forma absolutamente verosímil. Así, además, se añaden nuevas perspectivas y, en ocasiones, nuevos personajes. El autor implícito se sirve de todo ello para oxigenar el drama del náufrago, aderezándolo, en ocasiones, con un peculiar sentido del humor que el lector agradece?.

A esto hay que añadir un nuevo rasgo que pone de relieve el carácter literario, y que depende del autor implícito. Se trata de la expectación creada entre los capítulos -en un rasgo tomado del folletín- que responde a la que quería crear el reportero García Márquez para mantener el interés de sus lectores durante los catorce días que duró la serie en El Espectador de Bogotá. Sirva, a modo de ejemplo, el final del Capítulo 11, donde vemos a Velasco presa de las dudas ante la posibilidad de que la imagen que ha visto de la tierra sea una alucinación:

Ya me sentía sin fuerzas y, sin embargo, aún no veía la tierra. Entonces volvió a invadirme el terror: acaso, ciertamente, la tierra había

\footnotetext{
${ }^{9}$ A veces se trata de un sentido del humor vinculado al carácter moral del protagonista, al que se ha dotado de una capacidad especial para sacar el mejor partido de las situaciones más dramáticas.
} 
sido otra alucinación. El agua fresca me había reconfortado y yo estaba otra vez en posesión de mis sentidos, nadando desesperadamente hacia la playa de una alucinación. Ya había nadado mucho. Era imposible regresar en busca de la balsa (99).

Uno de los elementos esenciales de la literaturización, vinculado en este caso a la ficcionalidad, es el carácter moral que Luis Alejandro Velasco exhibe en el interior del relato, y lo es, precisamente, porque, como ya se señaló, queda desmentido en el prólogo que, no lo olvidemos, es un texto vinculado a la realidad al estar firmado por G. G. M. Ahí se descubre que, en alguna faceta, en alguno de sus rasgos, el náufrago es una invención del autor, una recreación anovelada que tiene elementos de la realidad y elementos imaginados. En el relato, Velasco aparece como un hombre bueno que no maldice su mala suerte, que descubre con gratitud lo que la vida le ofrece, que siente fuerzas renovadas para seguir adelante, que muestra su sencillez y su ingenuidad, y que no descubre cuánto vale su historia hasta que otros se lo hacen saber. Pero la imagen que se ofrece de él en el Prólogo es muy diferente, porque aparece como hombre de quien los lectores y el público están hartos, y como tipo interesado que trata de vender su historia para sacar provecho de ella:

Cuando Luis Alejandro Velasco llegó por sus propios pies a preguntarnos cuánto le pagábamos por su cuento, lo recibimos como lo que era: una noticia refrita (10).

Si venía a nosotros sin que lo llamáramos, después de haberlo buscado tanto, era previsible que ya no tenía mucho que contar, que sería capaz de inventar cualquier cosa por dinero, y que el gobierno le habría señalado muy bien los límites de su declaración (10-11).

Este tratamiento diverso del superviviente evidencia que en el relato periodístico se ha creado un personaje muy parecido al real que, sin embargo, tiene rasgos inventados por el autor. Nos encontramos ante una elaboración ficcional, y la ficcionalidad es una de las características esenciales de la literatura. Esta creación imaginaria del protagonista conviene al relato de 1955 porque el náufrago era el verdadero protagonista y el sujeto que interesaba al lector desde una perspectiva social. Sin embargo, en 1970 el que interesa es García Márquez, que se permite dinamitar la imagen del héroe levantada quince años antes y mostrar sin sonrojo que, al menos en parte, fue una invención suya. 
El autor implícito se sirve, además, de otros recursos que contribuyen a la literaturización del texto y que, al mismo tiempo, introducen variedad en un relato que resultaría monótono si sólo reprodujera lo acontecido al náufrago durante diez días a la deriva. Las alucinaciones de Luis Alejandro Velasco aparecen después de varias jornadas en las que está solo en el mar, temiendo por su vida a cada segundo. Todas ellas, vinculadas a la figura de su compañero Jaime Manjarrés, intercalan en el relato otras situaciones y otros personajes, y favorecen la entrada de lo mágico, así como la mezcla entre lo real (lo que sucede en la balsa) y lo ficcional (la ensoñación). La presencia de Manjarrés es para Luis tan real como el hambre y la sed, aunque fruto de la falta de lucidez. Además están las ensoñaciones del náufrago, que también permiten introducir otros tiempos, espacios y personajes, mientras facilitan la mezcla de realidad y fantasía en el relato, como afirma el mismo narrador en este fragmento:

Yo no sabía si era realidad o fantasía. Y todavía no me atrevo a decir si era realidad o fantasía, a pesar de que durante breves minutos vi nadar aquella gigantesca tortuga amarilla delante de la balsa, llevando fuera del agua su espantosa y pintada cabeza de pesadilla. Solo sé que -fuera realidad o fantasía- habría bastado con que tocara la balsa para que la hubiera hecho girar varias veces sobre sí misma (89).

Un ejemplo muy significativo de la mezcla entre realidad y fantasía tiene lugar cuando el protagonista, tras diez días de naufragio en solitario, por fin ve tierra. En ese momento de la historia, el personaje ha normalizado su precaria situación y se ha acostumbrado a ese estado de cosas. Por eso cuando vislumbra la costa, duda de si aquello es fantasía o realidad:

Sentí rabia. El día anterior me había visto en una fiesta en Mobile. Luego había visto una gigantesca tortuga amarilla, y durante la noche había estado en mi casa de Bogotá, en el colegio La Salle de Villavicencio y con mis compañeros del destructor. Ahora estaba viendo la tierra. Si cuatro o cinco días antes hubiera sufrido aquella alucinación me habría vuelto loco de alegría. [...] Pero en el estado en que yo me encontraba se estaba prevenido contra las alucinaciones. [...] Por eso no sentía alegría. Por eso me reafirmé en mis deseos de morir antes de que me volvieran loco las alucinaciones (96).

Finalmente, y en relación con esa mezcla entre fantasía y realidad, al final 
del relato el protagonista hace una apostilla que merece ser comentada:

He contado mi historia en la televisión y a través de un programa de radio. Además, se la he contado a mis amigos. Se la conté a una anciana viuda que tiene un voluminoso álbum de fotografías y que me invitó a su casa. Algunas personas me dicen que esta historia es una invención fantástica. Yo les pregunto: Entonces, ¿qué hice durante mis diez días en el mar? (119-120).

Sorprende que en la lista de receptores del suceso no esté el nombre de García Márquez, pero lo cierto es que en tal caso el lector no habría visto el relato como obra del náufrago y se habría desdibujado la verosimilitud sobre la autoría. Es decir, en la obra se busca, hasta el final, la sensación de realidad que aporta la narración en primera persona. Pero además está la alusión a la naturaleza fantástica de la historia, a su carácter inventado que, como se ve, preocupa al narrador hasta el último momento. Se trata, en definitiva, de uno de los aspectos más interesantes de la relación entre periodismo y literatura, y de un asunto que recorre de forma transversal el Relato de un náufrago ${ }^{10}$. La mezcla de ficción y realidad estaba ya presente en el texto de 1955, y el prólogo de 1970 refuerza aún más esa amalgama y nos obliga, como lectores, no a replantearnos si lo que se cuenta sucedió en realidad, sino a valorar, por encima de todo, la capacidad de un joven García Márquez que ya anticipa en un reportaje periodístico preocupaciones, motivos y valores que serán piezas clave de su literatura posterior.

\section{REFERENCIAS}

Clarke, G. 1993. Truman Capote. La biografía. Barcelona: Ediciones B. Chillón, A. 1999. Literatura y periodismo. Una tradición de relaciones promiscuas. Barcelona: Universidad Autónoma.

${ }^{10}$ Mario Vargas Llosa (1971: 43; apud Molina Fernández, 2006: 52) ha resumido acertadamente los valores de la obra: "Relato de un náufrago es un ligero pero excelente relato de aventuras, fraguado con un dominio maestro de todos los secretos del género: objetividad, acción incesante, toques hábilmente alternados de dramatismo, suspenso y humor [...]. Lo más arduo era describir los diez días vacíos e idénticos que pasó Velasco a la deriva, sin incurrir en repeticiones o caer en la truculencia. La dificultad fue salvada con una intuición de narrador que sabe organizar inteligentemente sus materiales y dosifica con cuidado la acción a lo largo del relato [...]. Todo es verosímil y conmovedor, sin ser nunca patético ni demagógico, por la eficacia del lenguaje que, aunque esencialmente informativo, tiene una limpieza y seguridad que delatan en su autor más aptitudes de narrador que de reportero". 
Díez Huélamo, B. 1986. Claves para la lectura de Relato de un náufrago de Gabriel García Márquez. México: Ediciones Daimon.

García Márquez, G. 1984 [1970]. Relato de un náufrago. Barcelona: Tusquets.

García Márquez, G. 2001. "Sofismas de distracción”, en Cambio, sección "Gabo contesta" de marzo. (En línea). Disponible en http://www.saladeprensa.org/art201.htm. Consulta: 26/04/2011.

Gilard, J. 1982. "Prólogo” a Gabriel García Márquez. En Obra periodística. Entre Cachacos 2. Madrid: Mondadori, pp. 7-68.

Méndez, J. L. 1989. Cómo leer a García Márquez: una interpretación sociológica. Puerto Rico: Editorial de la Universidad de Puerto Rico.

Molina Fernández, C. 2006. Gabriel García Márquez. Crónica y novela. Cáceres: Universidad de Extremadura.

Pérez Galdós, B. 2002. El crimen de la calle de Fuencarral. Madrid: Lengua de Trapo.

Vargas Llosa, M. 1971. García Márquez: historia de un deicidio. Barcelona: Barral Editores. 